\title{
A Review of the Trends and Causes of Food Insecurity in Ethiopia
}

\author{
Tariku Ayele \\ Lecturer and Researcher, Bule Hora University, Department of Agricultural Economics, Bule Hora, Ethiopia
}

\begin{abstract}
The issue of ensuring food security has become the agenda of concern across all over the globe especially for low income countries with high population growth rate. So far, a number of efforts have been made by governmental and non-governmental organization to reduce food-insecurity problems in Ethiopia and moreover, a number of food security/insecurity targeted studies have been conducted under different geographical locations of Ethiopia. However, these studies do not provide overall picture of food security or insecurity status at national level over a period of time as they entirely focused on household level food security/insecurity aspects. Therefore, the main aim of this paper was to provide national level data on the status, dynamics and causes of food insecurity in Ethiopia based on official reports and empirical evidences. Results from review shows that, even if food insecurity in the country has shown declining trend, still the percentage of food insecure people (32.7\%) is significant. The total food gap in the country is higher than that of other African countries. There are various sources and causes of food insecurity in Ethiopia. They include drought risk, environmental degradation, demographic pressure, ruralurban migration, and conflict. Moreover, household characteristics, limited asset ownership and access to institutional services, low participation in extension and other programs, and poor agricultural technology adoption are the other causes of food insecurity in Ethiopia. Benchmarking the compiled facts, it is possible to conclude that there still remains a number of efforts that should be made to improve food security status of food insecure people and enable them to have a better life through critically influencing four dimensions of food security both at micro and macro level.
\end{abstract}

Keywords: Status, Causes, Food Insecurity

DOI: $10.7176 /$ FSQM/99-02

Publication date:July $31^{\text {st }} 2020$

\section{Introduction}

The issue of ensuring food security has become the agenda of concern across the world in several contexts. Worldwide data shows that, number of people undernourished and severely food insecure people in 2018 was about 821.6 and 704.3 million people respectively. In the same year, in Africa, 256.1 and 277 million people respectively are undernourished and severely food insecure. In Ethiopia, average number of undernourished people in three years (From 2016-2018) is about 21.6 millions (FAOSTAT, 2019). According to ACAPS (2018), the number of food-insecure population in the country was increased from 5.6 million in December 2016 to 8.5 million in August 2017. Underlying vulnerability is also high, with four million people continuously dependent on the government's Protective Safety Net Programme (PSNP) for food assistance. Somali region in the southeast was the most affected in 2017 and is the most affected region in 2018. About 3.7 million people in the region are reliant on humanitarian food assistance (ACAPS, 2018).

According to World Bank (2017), even though the country has experienced high rates of economic growth which is estimated at $11 \%$ per annum, it has a low Human Development Index, ranking 174 out of 185 Ethiopians are categorized as living in poverty. Despite different policy efforts, many of the protracted and recurrent crises in Africa today are in pastoral areas, demonstrating that not enough is being done to sustainably address the vulnerability of these populations. Moreover, responses to crises in pastoralist areas are often late and inadequate, and humanitarian interventions are insufficiently linked to longer-term development (FAO, 2018). This indicates, there remains a further effort that has to be made to strengthen and empower pastoralist community so that they become stable in their livelihoods. "There is variability in estimates regarding the pastoralist community, as they are often an invisible demographic in both national and international statistics; however, the World Bank estimates there to be at least 12 million pastoralists and agro-pastoralists in the country of Ethiopia.

The economic contribution of the pastoralists has been consistently undermined but livestock trade contributes $45 \%$ of agricultural GDP in Ethiopia and $12 \%$ of national GDP. But, at least $19 \%$ of this comes from pastoralists" (Zeremariam and Dixon, 2017). Pastoralist communities generally live in isolated, remote and underdeveloped areas which make them food insecure. These areas are often conflict prone, food insecure and associated with high levels of vulnerability. Service provision in this area is usually less-well developed than in other areas, with low health and education indicators than national-level figures.

Given growing number of populations across all over the world, meeting food demand of growing population has became a subject of concern among policy makers, researchers, governments and non-governmental organization in developed and developing countries. As in other areas of Africa, population growth is also driving changes in pastoral areas and in some cases, increasing levels of vulnerability and destitution (AU, 2010; FAO, 
2018). In order to increase pastoralist resilience against adversity and protect and improve their lives and livelihoods, policy measures have been taken both continent-wide (in Africa) and nationwide (for example in Ethiopia). In Africa, policy framework for pastoralism in Africa is the first continent-wide policy initiative for mobilizing and coordinating political commitment to pastoral development in Africa, and emphasizes the need to fully involve pastoralist women and men in the national and regional development processes from which they are supposed to benefit (AU, 2010). Likewise, the issues of pastoralists mainstreamed in 1995 constitution of Ethiopia for the first time which shows governments' attention to pastoral development (Mohammed, 2015). In collaboration with World Food Program, it has also introduced Productive Safety Net Program to support food insecure households to build more resilient livelihoods and sustenance (Zeremariam and Dixon, 2017).

Moreover, in addition to actions taken by the government to increase pastoralist resilience, Ethiopian government has paid a due attention to food production, production insurance schemes and the commodity exchange, food aid, and price stabilization as a strategy to solve food insecurity problems in the country. Agricultural Transformation Agency and Productive Safety Net Program as means to increase food production and food availability during emergency situations including aforementioned strategies has been implemented (Häberli, 2013). Therefore, it gives a sense to evaluate progresses made by different stakeholders involved in food insecurity reduction efforts. In different parts of the country, a number studies on food security/insecurity have been conducted in Ethiopia. But, these studies do not provide overall picture of food security or insecurity status at national level as they entirely focus on household level food security or insecurity aspects. Moreover, they do not indicate the dynamics of food security or insecurity over a period of time. Therefore, given these facts, this paper intended to explore the status and dynamics of food insecurity and causes of food insecurity in Ethiopia, and suggest possible solutions helpful to increase food security and resilience based on empirical evidences.

\section{Objectives}

This review paper was initiated under the following objectives

1. To review trends and status of food insecurity in Ethiopia

2. To review and sort out causes of food insecurity in Ethiopia

\section{Empirical Reviews}

\subsection{Trends of Food Insecurity in Ethiopia}

The following table presents trends of food insecurity in Ethiopia taking in to account some of the main food security/insecurity indicators. The indicators incorporate four pillars of food security which includes food availability, access, stability and utilization. As indicated in the table 1, the average food production measured using per capita international dollar has shown increasing trend from \$105 per person in 2010 to $\$ 114$ per person in 2015 . But, in 2016 the average food production has fallen to $\$ 75$ per person. Eight years trend in the number of people undernourished shows that, the number of people who are undernourished has declined from 28.1 million people in 2010 to 21.6 million people in 2017 (FAOSTAT, 2018). Trends in per capita income (GDP per capita) measured using constant international dollar in 2011 indicates, there is an increase in GDP per capita by $\$ 719.7$ from 2010 to 2018. Moreover, even if their coverage is still limited, percentage of the population using sanitation services and basic drinking water respectively are has shown slight increase from the base year to 2017. Percentage of the children under five years of age who are stunted has decreased by $5.8 \%$ from $44.2 \%$ in 2011 to $38.4 \%$ in 2016 (FAOSTAT, 2018). 


\begin{tabular}{|l|l|l|l|l|l|l|l|l|c|}
\hline Indicators & $\mathbf{2 0 1 0}$ & $\mathbf{2 0 1 1}$ & $\mathbf{2 0 1 2}$ & $\mathbf{2 0 1 3}$ & $\mathbf{2 0 1 4}$ & $\mathbf{2 0 1 5}$ & $\mathbf{2 0 1 6}$ & $\mathbf{2 0 1 7}$ & $\mathbf{2 0 1 8}$ \\
\hline $\begin{array}{l}\text { Average food production } \\
\text { (\$/person) }\end{array}$ & 105 & 109 & 109 & 111 & 114 & 114 & 75 & - & - \\
\hline $\begin{array}{l}\text { Average dietary energy } \\
\text { supply adequacy (\%) }\end{array}$ & 96 & 97 & 98 & 100 & 102 & 103 & 104 & 105 & - \\
\hline $\begin{array}{l}\text { Number of people } \\
\text { undernourished (million) }\end{array}$ & 28.1 & 27.6 & 26.7 & 25.3 & 23.8 & 22.7 & 21.9 & 21.6 & - \\
\hline $\begin{array}{l}\text { GDP per capita (constant } \\
\text { 2011 \$I) }\end{array}$ & 1074.6 & 1161.6 & 1226.8 & 1318.8 & 1414 & 1518.5 & 1617.3 & 1724.5 & 1794.3 \\
\hline $\begin{array}{l}\text { Population using } \\
\text { sanitation services (\%) }\end{array}$ & 5.7 & 5.9 & 6.2 & 6.4 & 6.6 & 6.9 & 7.1 & 7.3 & - \\
\hline $\begin{array}{l}\text { Population using basic } \\
\text { drinking water (\%) }\end{array}$ & 33 & 34.3 & 35.6 & 36.7 & 37.9 & 39 & 40 & 41.1 & - \\
\hline $\begin{array}{l}\text { Stunted children under 5 } \\
\text { years of age (\%) }\end{array}$ & \multicolumn{1}{|c|}{44.2} & - & - & 40.4 & - & 38.4 & - & - \\
\hline $\begin{array}{l}\text { Per capita food production } \\
\text { variability (\$I/capita) }\end{array}$ & 3000 & 3700 & 3700 & 3100 & 2700 & 2300 & 1600 & & - \\
\hline
\end{tabular}

Table 1: Trends of food insecurity in Ethiopia

Note: Hyphen denotes missing data

Source: FAOSTAT, 2018

\subsection{Trends of Food Security Targeted Emergency Relief Expenditure in Ethiopia}

In response to temporal food insecurity problem across the country, expenditures on the several emergency relief programs have been made by governments and donor agencies. As mentioned in table 2, the type of relief assistances given during emergency include food, targeted supplementary feeding especially to infants and pregnant women, health and nutrition, water and sanitation services, agriculture and livestock services, school feeding, protection, and emergency shelter (In case there are natural and manmade displacements during disasters) (NPC, 2017). According to NPC (2017), the total monetary expenditure has increased from 9.3 billion Birr to 9.7 billion Birr between 2010 and 2011. The statistics also shows that the size of monetary expenditure has reached a highest level of over 13.1 billion in 2016 and over 16.8 billion Birr in 2017 due to the rapid increase in emergency relief recipients following severe drought during 2016. In terms of the amount of expenditure, from the various components of the emergency relief expenditures, food assistance accounts the lion's share with an average of over $78 \%$ between 2010 and 2017 followed by health and nutrition support and targeted supplementary feeding (NPC, 2017).

\begin{tabular}{|l|c|c|c|c|c|c|c|c|}
\hline $\begin{array}{l}\text { Type of Relief } \\
\text { Assistance }\end{array}$ & $\mathbf{2 0 1 0}$ & $\mathbf{2 0 1 1}$ & $\mathbf{2 0 1 2}$ & $\mathbf{2 0 1 3}$ & $\mathbf{2 0 1 4}$ & $\mathbf{2 0 1 5}$ & $\mathbf{2 0 1 6}$ & $\mathbf{2 0 1 7}$ \\
\hline Food & $7,937.36$ & $7,886.60$ & $3,697.57$ & $3,398.66$ & $4,912.21$ & $3,943.41$ & $10,194.5$ & $15,126.3$ \\
\hline $\begin{array}{l}\text { Targeted } \\
\text { supplementary } \\
\text { feeding }\end{array}$ & 793.42 & 854.24 & 588.43 & 182.58 & 414.14 & 276.57 & 274.62 & 0.00 \\
\hline $\begin{array}{l}\text { Health and } \\
\text { Nutrition and }\end{array}$ & 375.45 & 516.37 & 362.38 & 322.71 & 311.59 & 451.69 & $1,225.52$ & 757.61 \\
\hline $\begin{array}{l}\text { Water and } \\
\text { sanitation }\end{array}$ & 148.05 & 170.95 & 102.18 & 210.80 & 163.74 & 191.32 & 543.33 & 271.71 \\
\hline $\begin{array}{l}\text { Agriculture } \\
\text { livestock }\end{array}$ & 0.00 & 65.14 & 53.76 & 68.13 & 66.66 & 33.10 & 120.27 & 98.00 \\
\hline School feeding & 0.00 & 0.00 & 0.00 & 0.00 & 0.00 & 0.00 & 66.44 & 69.83 \\
\hline Protection & 0.00 & 0.00 & 0.00 & 0.00 & 0.00 & 0.00 & 45.79 & 48.12 \\
\hline Emergency shelter & $\mathbf{9 , 3 5 0 . 1 0}$ & $\mathbf{9 , 7 6 3 . 4 3}$ & $\mathbf{5 , 0 5 5 . 8 8}$ & $\mathbf{4 , 4 2 6 . 2 0}$ & $\mathbf{6 , 0 2 6 . 6 1}$ & $\mathbf{5 , 2 0 5 . 8 6}$ & $\mathbf{1 3 , 1 2 6 . 3}$ & $\mathbf{1 6 , 8 0 2 . 4}$ \\
\hline $\begin{array}{l}\text { Total emergency } \\
\text { relief expenditure }\end{array}$ & & & & & & & & \\
\hline
\end{tabular}

Table 2: Trends in emergency relief aid in Ethiopia (in millions at 2011prices)

Source: NPC, 2017

\subsection{Food Insecurity State of Ethiopia in East African Context}

The following table shows comparison of Ethiopia's food insecurity position against other East African countries in selected indicators. In East Africa, out of 353 million people in 2019, 142.4 million (40.3\%) people were food insecure. The number of food insecure people expected to be reduced to 90 million out of estimated 446 million 
people in 2029. Given population differences across countries in East Africa, the percentage of food insecure people in Ethiopia is lesser than that of the remaining countries except Kenya with $32.7 \%$ food insecure people during the period of 2019. The percentage of food insecure people in Ethiopia expected to fall to only $7 \%$ in 2019 . Countries like Eritrea, Burundi, Chad, Tanzania and Sudan are East African countries with significant percentage of food insecure people. In terms of food gap measured in per capita kilo calorie per day, Ethiopia ranks the second next to Kenya (311 Kcal/day) with per capita kilo calorie per day of 346 in 2019 . But, the size of food gap measured in thousands metric ton grain equivalents in Ethiopia during the same year is higher than other countries.

\begin{tabular}{|c|c|c|c|c|c|c|c|c|c|c|}
\hline & \multicolumn{2}{|c|}{$\begin{array}{l}\text { Population } \\
\text { (Million) }\end{array}$} & \multicolumn{2}{|c|}{$\begin{array}{l}\text { Population } \\
\text { food insecure } \\
\text { (Million) }\end{array}$} & \multicolumn{2}{|c|}{$\begin{array}{c}\text { Population } \\
\text { food insecure } \\
(\%)\end{array}$} & \multicolumn{2}{|c|}{$\begin{array}{c}\text { Food gap (per } \\
\text { capita, } \\
\text { Kcal/day) }\end{array}$} & \multicolumn{2}{|c|}{$\begin{array}{c}\text { Total food gap } \\
\text { (Grain } \\
\text { equivalents, } \\
\text { 1000MT) }\end{array}$} \\
\hline & 2019 & 2029 & 2019 & 2029 & 2019 & 2029 & 2019 & 2029 & 2019 & 2029 \\
\hline $\begin{array}{l}\text { East } \\
\text { Africa }\end{array}$ & 353 & 446 & 142.4 & 90.0 & 40.3 & 20.2 & 445 & 407 & 7,458 & 4,306 \\
\hline Ethiopia & 111 & 145 & 36.5 & 10.1 & 32.7 & 7 & 346 & 240 & 1,396 & 268 \\
\hline Burundi & 12 & 17 & 8.6 & 11.5 & 70.4 & 68.5 & 516 & 505 & 518 & 673 \\
\hline Chad & 13 & 15 & 7.7 & 6.9 & 61.1 & 46.5 & 679 & 589 & 643 & 505 \\
\hline Eritrea & 6 & 7 & 5.8 & 5 & 96.4 & 74.5 & 803 & 511 & 580 & 319 \\
\hline Kenya & 49 & 56 & 14.3 & 3.7 & 29.1 & 6.6 & 311 & 223 & 530 & 98 \\
\hline Rwanda & 12 & 15 & 4.1 & 2 & 32.8 & 13.7 & 399 & 316 & 190 & 74 \\
\hline Somalia & 12 & 15 & 5.8 & 7.1 & 50.1 & 48.3 & 488 & 479 & 322 & 389 \\
\hline Sudan & 39 & 46 & 21.9 & 13.9 & 56.8 & 30.4 & 470 & 359 & 1,248 & 602 \\
\hline Tanzania & 57 & 74 & 21.1 & 19.6 & 37 & 26.4 & 479 & 429 & 1,137 & 944 \\
\hline Uganda & 42 & 57 & 16.7 & 10.2 & 39.6 & 18 & 450 & 354 & 895 & 432 \\
\hline
\end{tabular}

Table 3: Comparison of Ethiopia with other East African countries in some food security indicators

Source: Thome et al., 2019

\section{The Causes of Food Insecurity in Ethiopia}

There are various causes of food insecurity in Ethiopia including drought risk, environmental degradation, demographic pressure, rural-urban migration, and conflict. In the absence of adaptation measures, climate variability and change act as risk multipliers, exacerbating the conditions which affect food security trends. One of the causes of food insecurity in Ethiopia is climate change. All rural livelihood systems in Ethiopia are highly sensitive to climate given the dependence of cropping, pastoral and agro-pastoral communities on rainfall. With a predominantly rain-fed agricultural system, rainfall is one of the main climatic determinants of food production and access in Ethiopia (FAO, 2018). Across most parts of the Ethiopia, erratic rainfall is reported as the main risk contributing to their food insecurity and overall vulnerability. Especially, in the pastoral areas, where rainfall has become increasingly erratic, the amount of food production and access is low making them food insecure. Droughts and floods are other causes. According to FAO (2018), in Ethiopia, prolonged drought conditions are severely affecting the livelihoods in southern and southeastern pastoral and agro-pastoral areas of SNNPR, southern Oromia and southeastern Somali Regions, where cumulative seasonal rainfall was up to $60 \%$ below average. In these areas, pasture and water availability have declined to extremely low levels, severely affecting crop production and livestock conditions, leading to large scale animal deaths. Historical and more recent climate-related events such as the 2009 and 2011 food security crises in the Horn of Africa have highlighted the impact of droughts and floods on food production, access to markets, and income from agricultural activities (CCAF and WFP, n.d).

Similarly, chronology of food insecurity in Ethiopia shows that drought risk remains one of the key drivers of food insecurity in Ethiopia. Since 1950, twelve major drought-induced food security crises have occurred. Drought is prevalent particularly in the regions of Afar (which has a climate similar to that of the Sahel), Somali, and south and eastern Oromia (which have a climatological pattern similar to that of the Greater Horn/equatorial Eastern Africa). Floods (both riverine and flash floods) are also key risks, affecting water quality and quantity, and resulting in loss of lives and livelihoods, increases in animal disease outbreaks, lower purchasing power, migration, and social disruption. While flood risk has traditionally been an issue of concern in farming areas, in recent years, pastoralist areas have also been affected by floods indicating the changing risk environment in Ethiopia (CCAF and WFP, n.d; FSIN, 2017).

Conflict is a leading cause of food insecurity and hunger in several parts of the world, undermining food security in multiple ways and creating access problems for governments and humanitarian agencies who often struggle to reach those most in need. According to FSIN (2018), conflict and insecurity are the major drivers of food insecurity in eighteen countries, and the number of food-insecure people across the world has been increasing over time. Likewise, food security situation in Ethiopia deteriorated sharply in 2017. The causes of food insecurity 
in conflicts are diverse but often coupled to disruptions in food production and food systems, plundering of crops and livestock, loss of assets and incomes or population displacement which all directly or indirectly impact availability, access and utilization of food. In general, in conflict-affected areas, the lack of adequate access to food has an immediate detrimental effect on malnutrition (FSIN, 2017). According to FAO et al., (2017), much of the recent increase in food insecurity can be traced to the greater number of conflicts.

Environmental degradation is also a critical factor which exacerbates soil loss, deforestation, and pest incidence all of which are affect food security. Land degradation is seriously affecting the soil fertility, contributing to considerable yield decline, loss in food production, and hence the food security at household and country levels. In addition, rapid population growth, poverty, and rural-urban migration can contribute to food insecurity (CCAF and WFP, n.d). In Ethiopia, smallholder farming is the dominant livelihood activity and the source of vulnerability to poverty and food insecurity. Infrastructure in terms of adequate energy and water/irrigation supplies, high-speed communications, and seamless transportation systems connecting areas of high production with centers of high consumption, all play a crucial role in safeguarding food security. But, much of that food loss occurs during or after harvest in developing countries due to inadequate infrastructure, lack of proper storage facilities, lack of education on grain storage and lack of efficient markets to ensure grains move through the supply chain. This food loss reduces incomes of smallholder farmers, raises food prices and contributes to hunger and malnutrition. Some regions in Ethiopia produce surplus, while people in other regions face famine threats (Birara, Gashaw, and Solomon, 2016). According to Feed the Future (2018), the primary direct and indirect causes of malnutrition in Ethiopia include persistent food insecurity, poor dietary diversity, poor food quality/safety, poor maternal and child feeding practices, suboptimal hygiene and sanitation, cultural practices, and limited access to quality nutrition services.

Different authors have studied determinants of food security and food insecurity in different parts of the Ethiopia. Empirical evidences on determinants of food security and insecurity in the country indicates that variables like sex of households, age, education status, family size, dependency ratio, total annual income, land size owned, number of livestock owned, oxen owned, use of improved seed, soil fertility status, non-farm income, fertilizer use, agro-ecology stratum, access to veterinary services, amount of credit received, mobility, participation in safety nets, distance to market areas and remittances, and access to quality of drinking water (Alem, 2007; Hussein and Janekarnkij, 2013; Ahmed, 2015; Zeid, Kalkidan and Tolassa, 2016).

\section{Conclusion}

This review was mainly initiated to explore recent and updated information regarding the status and causes of food insecurity in Ethiopia as means to evaluate progresses made by government and non-governmental organizations to tackle food insecurity problems in the country. The result from review study shows that, based on the various food insecurity indicators, on average, there is a reduction in food insecurity in Ethiopia over a period of time. Even if food insecurity in the country has shown declining trend, still the percentage of food insecure people $(32.7 \%)$ is significant. The total food gap in the country is higher than that of other African countries. There are various sources and causes of food insecurity in Ethiopia. They include drought risk, environmental degradation, demographic pressure, rural-urban migration, and conflict. Moreover, household characteristics, limited asset ownership and access to institutional services, low participation in extension and other programs, and poor agricultural technology adoption are the other causes of food insecurity in Ethiopia. Benchmarking the compiled facts, it is possible to conclude that there still remains a number of efforts that should be made to improve food security status of food insecure people and enable them to have a better life through critically influencing four dimensions of food security both at micro and macro level. Based up on the scope of the variables studied, different researchers have suggested enhancing households' access to financial and social capital, creation of public awareness on family planning, strong and effective extension system to enhance farmers' adoption of agricultural technologies and improving farmers' access and use of fertilizer, improved seed varieties, irrigation water, extension service, pre and post-harvest management of agricultural products, investment on household education, enhancing households entrepreneurial skill to engage in different income generating activities to diversify livelihood options, use of coping mechanisms, encouraging the farmers to develop and adopt soil and water conservation measures to reduce soil erosion, improve and maintain soil fertility, and to enhance the habit of using rain water harvesting to alleviate problems caused by shortage of rain fall and incorporating different research outputs to design programs for food insecurity intervention.

\section{References}

ACAPS (2018). $\quad$ Food $\quad$ insecurity. Retrieved from https://www.acaps.org/sites/acaps/files/slides/files/20180226_acaps_thematic_report_food_insecurity_final. pdf

Ahmed Mohammed, (2015). Determinants Of Household Food Security and Coping Strategies: The Case of BuleHora District, Borana Zone, Oromia, Ethiopia, European Journal of Food Science and Technology Vol.3, 
No.3, pp.30-44, July 2015

Alem Shumiye, (2007). Determinants of Food Insecurity in Rural Households in Tehuludere Woreda, South Wello Zone of the Amhara Region. Master's Thesis, School of Graduate Studies, Addis Ababa University.

AU (African Union) (2010). Policy Framework For Pastoralism In Africa: Securing, Protecting and Improving The Lives, Livelihoods And Rights Of Pastoralist Communities

Birara Endalew, Gashaw Tenna, and Solomon Bizuayehu. (2016). State Of Household Food Insecurity in Ethiopia: Review, A Journal of Radix International Educational and Research Consortium, Volume 4, Issue 12

Climate Change Agriculture and Food Security and World Food Program. (n.d). Climate risk and food security in Ethiopia: Analysis of climate impacts on food security and livelihoods.

FAO (2018). Global Early Warning - Early Action Report on Food Security and Agriculture. Retrieved from https://reliefweb.int/report/world/global-early-warning

FAO (Food and Agriculture Organization). (2018). Pastoralism in Africa's drylands: Reducing risks, addressing vulnerability and enhancing resilience, Rome. 52 pp. Licence: CC BY-NC-SA 3.0 IGO.

FAO, IFAD, UNICEF, WFP and WHO. (2017). The State of Food Security and Nutrition in the World 2017. Building resilience for peace and food security, Rome.

Feed the Future. (2018). Global Food Security Strategy (GFSS): Ethiopia Country Plan

FSIN (2018). Global Report on Food Crises. Retrieved from http://www.fao.org/emergencies/resources/documents/resourcesdetail/ en/c/1107313/

Häberli C., (2013). Ethiopia's Food Reserve Policies and Practice. Working Paper No 2013/02.

Hussein W., and Janekarnkij P. (2013). Determinants of Rural Household Food Security in Jigjiga District of Ethiopia, Kasetsart J. (Soc. Sci) $34: 171-180$.

Marion N (2011). Towards A Food Insecurity Multidimensional Index. Retrieved from https://www.semanticscholar.org/paper/Towards-a- $\quad$ Food-Insecurity-Multidimensional-Index-(-NapoliMuro/e37dad6f2c3e6d3f159ab68e6c7867b3ea3034ad

Mohammed Yimer, (2015). Pastoral Development Pathways in Ethiopia; the Policy Environment and Critical Constraints, Brief for GSDR.

NPC. (2017). Ethiopia's Progress Towards Eradicating Poverty: An Interim Report on 2015/16 Poverty Analysis Study, Addis Ababa Ethiopia

Thome, Karen, Michael D. Smith, Kamron Daugherty, Nicholas Rada, Cheryl Christensen, and Birgit Meade. (2019). International Food Security Assessment, 2019-2029, GFA-30, U.S. Department of Agriculture, Economic Research Service.

Zeid Jemal, Kalkidan Hassen and Tolassa Wakayo. (2016). Household Food Insecurity and its Association with Nutritional Status among Preschool Children in Gambella Town, Western Ethiopia. Journal of Nutrition \& Food Sciences, 6:6

Zeremariam Fre and Dixon N, (2017). Social protection among the Afar pastoral and agro-pastoral communities in Ethiopia: Critical reflections on the multi-partner efforts, achievements, challenges and some lessons learnt, SPIDA WORKING PAPER SERIES - ADU/PENHA/DPU-UCL SPIDA/WPS/104/2017 